\title{
Nueva interpretación de los estabilizadores anatómicos en la fractura de muñeca. Parte I: Evolución de la región de la muñeca y nueva clasificación de las fracturas de radio
}

\author{
J. M. Rotella, P. Rotella \\ Servicio de Cirugía Ortopédica y Traumatología Sanatorio del Norte. San Miguel de Tucumán. Argentina.
}

Resumen: En este trabajo se presenta una nueva interpretación personal de las lesiones de muñeca basada en el estudio de la filogenia, embriología, anatomía y biomecánica de esta región y en base a esta nueva interpretación planteamos una nueva clasificación (parte I del trabajo), que ayudará a entender los patrones lesionales de las distintas fracturas (parte II del trabajo) y a definir una nueva "estrategia" para el tratamiento de las fracturas de radio (parte III del trabajo).

El eje post-axial es el encargado del desarrollo del miembro superior. El carpo y la mano siempre estuvieron articulados al cúbito y para que pueda aparecer el movimiento de supinación, parte del carpo necesitó migrar al radio.

Se describen tres sectores en la región de la muñeca: cubital (interno); central (medio) y radial (externo); cada uno de ellos presentan diferentes orígenes: evolutivo, formativo, constitutivo y funcional.

Cada sector tiene un rol biomecánico diferente, de los que surgen diferentes "patrones" de lesión. Estos distintos patrones producen desplazamientos e inestabilidades en las diferentes zonas que responden al origen filogénico de cada uno de los estabilizadores anatómicos.

Cuando sucede un traumatismo en la muñeca, las fuerzas se distribuyen de forma diferente en los tres sectores de la muñeca. En el sector externo, es decir, en el radio, se producen fuerzas de "compresión". En el sector interno, los ligamentos y estiloides del cúbito, actúan fuerzas de "distracción".

Palabras claves: Evolución de la muñeca. Patrones de lesión. Fractura de muñeca.

\section{New interpretation of the anatomical stabilizers in wrist fractures. Part I: development of the wrist and new radial fracture classification.}

\begin{abstract}
In this work a new and personal interpretation of the wrist's fractures is presented based on the study of the phylogeny, embryology, anatomy and biomechanics of this area and based on this new interpretation we set up a new clasification (part I), that will help to understand the injury patterns of the different fractures (part II) and to define a new "strategy" for the treatment of the radial fractures (part III).

The postaxial axis is in charge of the development of the upper limb. The carpus and the hand were always articulated to the ulna and in order to allow the supination movement to appear, a portion of the carpus needed to pass to the radius. The areas are described in the wrist's region: ulnar (internal); central (middle) and radial (external); each one of them present different origins: evolutive, formative, constitutive and functional.

Each area has biomechanical different role, from where it emerges different "patterns" of injury. These different patterns produce shifts and instabilities in the different areas that respond to the phylogeny origin of each one of the anatomical stabilizer.

When a trauma is produced in the wrist, the strengths are distributed differently in the three areas of the wrist. In the external area, the bone (radius), "compression" strengths are produced and in the internal area, ligaments and ulnart styloid, "distraction" strengths act.
\end{abstract}

Key words: Wrist's evolution. Injury patterns. Wrist's fracture.

Desde la primera descripción 1783 por Pouteau de una fractura de muñeca, se han publicado múltiples artículos referentes a los desplazamientos y conductas a tomar en esta patología.

En las últimas décadas con el aumento de la siniestralidad, aumentó la incidencia en adultos jóvenes y adolescentes ya que, anteriormente en su mayoría, estas lesiones eran en mujeres postmenopáusicas.
Presentamos una interpretación diferente respecto a la distribución de las "fuerzas" en el momento del trauma; y también del papel estabilizador de los ele-

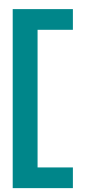


mentos anatómicos en la región de la muñeca. El hacer un diagnóstico correcto de la lesión de cada uno de estos elementos y su magnitud, es importante para lograr un correcto tratamiento de la fractura.

Esta interpretación diferente de la región de la muñeca, surge del estudio de la "evolución filogenética" y de la "embriología", que dieron origen a la anatomía que hoy conocemos.

Actualmente existen innumerables clasificaciones de las fracturas de muñeca, que recomiendan distintas conductas terapéuticas según el tipo de lesión. Muchas de estas clasificaciones se fundamentan en la cantidad de fragmentos, en los desplazamientos de los mismos en la afectación o no de la superficie articular, etc.

Actualmente se entiende que las fuerzas que impactan en la muñeca en el momento del traumatismo, producen el desplazamiento hacia externo y la angulación dorsal del radio distal. Esta deformidad y desplazamiento, está favorecida por el debilitamiento de la arquitectura ósea, debido a la osteoporosis en un alto número de pacientes.

Las fuerzas de "compresión" se producen sobre el radio y las fuerzas de "distracción" sobre el cúbito. Las lesiones del borde cubital, pueden afectar a distintas localizaciones de la estiloides e implicar distintos estabilizadores. Presentamos un estudio de casos clínicos, con el objeto de caracterizar las líneas de fractura, el grado de conminución y el desplazamiento de los fragmentos; tomando a estos como parámetro en la estabilidad de cada sector; surgen patrones de lesión.

\section{FILOGENIA}

El miembro anterior en la evolución ha sufrido cambios importantes. En la adaptación a nuevos requerimientos la muñeca ha sufrido algunos de estos cambios que han permitido tener los movimientos que hoy conocemos.

Cuando se realiza un estudio exhaustivo y meticuloso de la anatomía comparada ${ }^{1-4}$ se comprueba que el carpo se articulaba con el cúbito y que el eje postaxial fue el formador de todo el carpo y la mano.

"El carpo y la fosa del semilunar migró del cúbito al radio". De allí el "doble origen embrionario de la epífisis distal del radio".
El cúbito (eje post-axial) proximalmente está articulado con el húmero en la tróclea, esto solo le permite pequeños movimientos rotacionales sobre su eje. El eje post-axial distalmente, sería el formador de todos los huesos del carpo. Solo uno de estos huesos (radial o escafoides) se articulaba con el radio, los restantes se articulaban con el cúbito.

Esta morfología tampoco le permitía movimientos de rotación. En estas condiciones todo el miembro anterior: el brazo, el antebrazo, el carpo y la mano, actuaban como un segmento semirrígido, sin rotaciones. Esta condición, en animales que apoyan y no necesitan la supinación, es muy buena, porque la rigidez de los segmentos permite el ahorro energético en la fase de estancia del miembro y muy buena estabilidad en el apoyo en pronación.

¿Cuándo y por qué, se produjeron las modificaciones que hoy conocemos en la morfología de la región de la muñeca? La respuesta es, cuando hizo falta o fue necesario supinar ${ }^{3}$. Cuando se produce la bipedestación y el tren superior se libera, comienzan a producirse los cambios fundamentales, tanto biomecánicos como morfológicos que hoy conocemos. Hasta entonces, el cúbito era el hueso fundamental y el radio estaba a la par, como el peroné en el miembro inferior (pre-axial-zengopodio).

Para lograr el tercer movimiento del espacio (pronosupinación), se transfirió toda la articulación del semi-

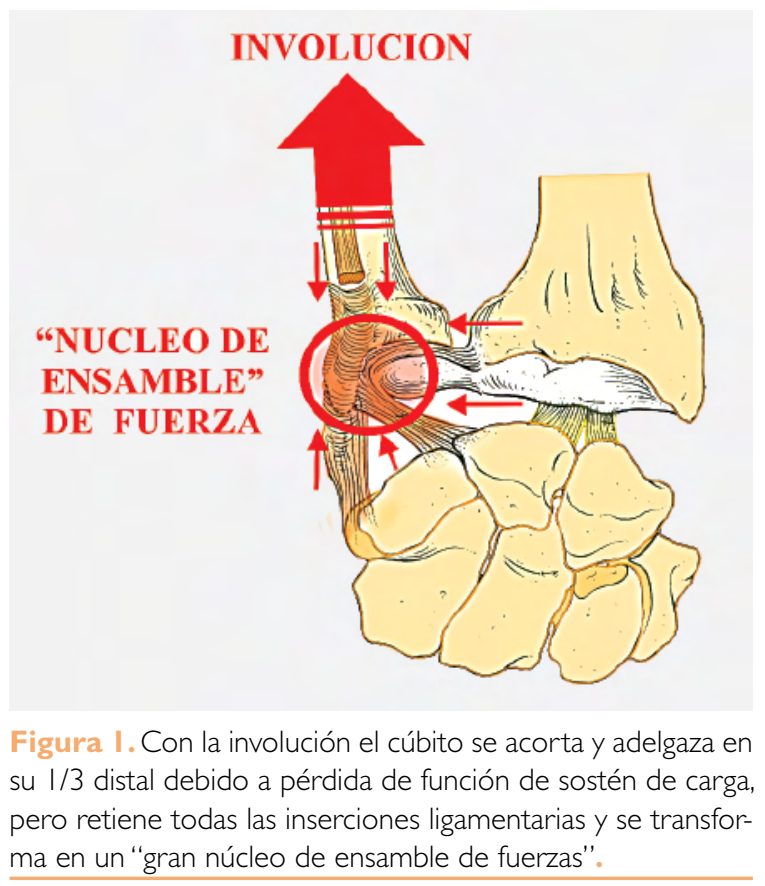




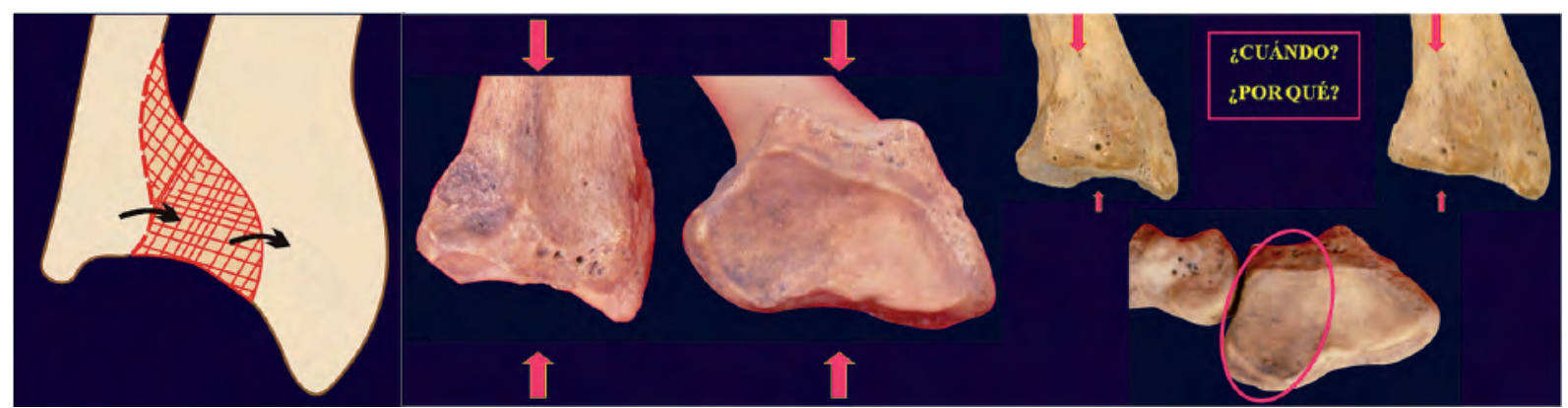

Figura 2. Preparación anatómica, donde se marca el "punto de unión" de la migración del cúbito al radio. En el dorso de la epífisis distal del radio, se observa el "borde de unión" que corresponde al tubérculo de Lister.

lunar al radio. Con esto se logró que todo el carpo se independice del eje del miembro, comience a girar junto con el radio y se permita enfrentar la palma de la mano con la cara.

La aparición de la supinación sucedió con otros cambios generales y particulares del miembro superior como la bipedestación (que libera al miembro anterior) y la mejora de la función de la mano: con la prensión, oposición y sensibilidad.

Cuando realizamos la búsqueda de los primeros cambios en la morfología ósea mediante estudios paleontológicos, que nos permitan inferir cuándo comenzó la supinación, descubrimos que los primeros cambios sucedieron en la morfología de la paleta humeral, con la aparición del cóndilo humeral y este cambio aparece rudimentariamente en los cinodontes.

\section{INVOLUCIÓN DEL CÚBITO}

En este "proceso de involución del cúbito", el hueso se acorta y se adelgaza en su 1/3 distal debido a pérdida de función de sostén de carga ${ }^{3}$ El cúbito disminuye su volumen, pero retiene todas las inserciones ligamentarias con el carpo. Se transforma en un "gran núcleo de ensamble de fuerzas" (- Figura I. Mantiene todos los estabilizadores pasivos ligamentosos (tenodésicos) y dos grandes estabilizadores activos (músculo-tendinosos). El primero, insertado en el dorso, es el Extensor Cubital del Carpo (inervado por el nervio radial) y el segundo es el Flexor Cubital del Carpo (inervado por el nervio cubital). Estos tendones transcurren sobre el borde cubital de la muñeca y terminan insertándose distalmente casi a la misma altura, uno en la base del $5^{\circ}$ metacarpiano y el otro en el pisiforme. Con esto se garantiza, la mayor estabilidad posible de la muñeca a nivel de la articulación radio-cubital distal (RCD), con la acción de dos potentes músculos (uno volar y otro dorsal).

Durante este proceso involutivo cubital, se transfirió todo el carpo al radio, por lo que el cúbito pasó a tener un rol estabilizador (arbotante), en los movimientos de prono-supinación, que tiene que realizar el radio alrededor del cúbito. Por este motivo, los ligamentos que unen el carpo con el cúbito son tan importantes.

¿Cuándo la "sinostosis" entre el cúbito y el radio pasó a ser una articulación? Aparece la articulación Radiocubital proximal (macho sobre hembra), la membrana interósea y la articulación Radiocubital distal (hembra sobre macho). Aparece el fibrocartílago triangular, que juega un papel fundamental en el giro que realiza el radio alrededor del cúbito y el cúbito distal, se mantiene como punto sobre el que se producen los giros del carpo y la mano en la prono-supinación.

En este momento sucedió una gran modificación en la arquitectura ósea de la muñeca, la parte más radial del cúbito distal migró al radio distal. Todo lo que hoy corresponde a la fosa del semilunar, se unió al resto de la epííisis distal del radio (fosa del escafoides), formando en el punto de unión una cresta conocida hoy como Tubérculo de Lister (- Figura 2.

Esta migración ósea también llevó consigo las inserciones ligamentosas, esto explica la dirección oblicua de los ligamentos desde el borde dorsal de la fosa del semilunar al carpo. Todos los movimientos de inclinación y pronosupinación, son estabilizados por ligamentos que unen el carpo con el cúbito a través de los ligamentos estilo-carpiano y cubito-carpiano y el radio con el cúbito, a través del fibrocartílago triangular. Por eso la porción cubital de la muñeca, anatómicamente es "ligamentaria" y biomecánicamente es estabilizador de las fuerzas de distracción y todo el 


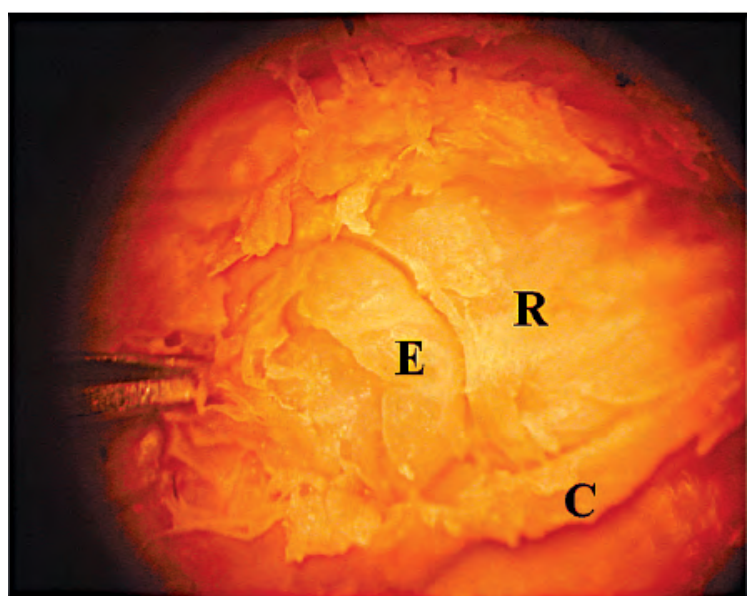

Figura 3. Disección de la muñeca en un feto fresco de 5 semanas. La región de la muñeca comienza la "cavitación" de la primera y segunda fila del carpo. Las epífisis distales del radio (R) y del cúbito (C) no se encuentran separadas.

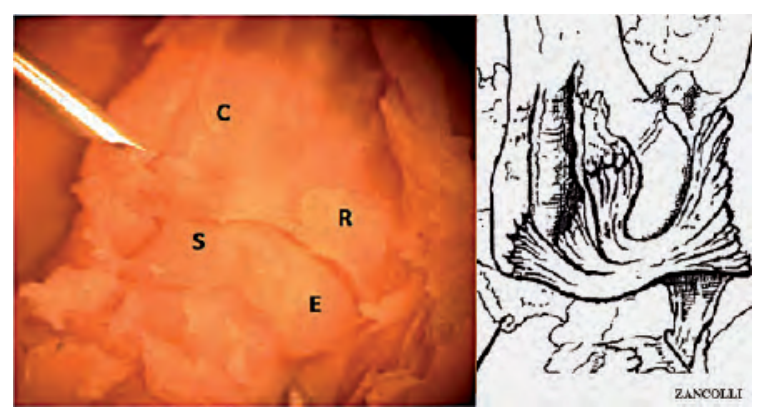

Figura 4. Disección de la muñeca en un feto fresco de 9 semanas. Se evidencian los fuertes estabilizadores desde la estiloides del cúbito y no así desde el sector externo del radio. El del "complejo ligamentario" une el extremo distal del cúbito, con el radio y el carpo ("núcleo de ensamble de fuerzas").

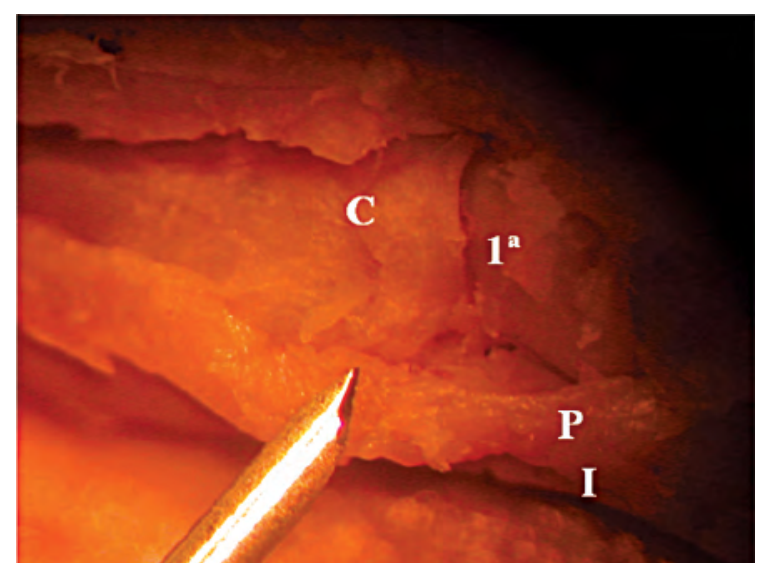

Figura. 5. Vista lateral del borde cubital de la muñeca, donde se muestran los fuertes elementos anatómicos, que estabilizan el carpo desde el dorso del cúbito (C); (P) pisiforme; $\left(I^{a}\right)$ primera fila del carpo. (Laboratorio de Investigación Anatómica del Sanatorio del Norte). núcleo de ensamble mantiene suspendido al carpo desde la apófisis estiloidea del cúbito.

De esta nueva reinterpretación de la evolución que sufrió la región de la muñeca, surge otra asignación del rol que cumple cada uno de los elementos constitutivos de esta zona.

\section{EMBRIOLOGÍA}

Durante la maduración de la epífisis distal del radio en su núcleo de crecimiento, se evidencian diferencias significativas, entre su borde interno y externo ${ }^{5-7}$, (c) Figuras 3, 4 y 5. Esto ya está perfectamente descrito en el Atlas de Greulich-Pyle ${ }^{8}$.

El origen de esta epífisis distal del radio, recuerda el doble origen al que hemos hecho mención, que explica cómo la parte cubital de esta epífisis, migró desde el eje post-axial y fue está "migración funcional" la que permitió la pronosupinación.

El eje post-axial es desde el que se organiza la formación y el desarrollo del miembro superior. El carpo siempre estuvo articulado con el cúbito 1,24. Para que pueda aparecer el movimiento de supinación, el carpo necesitó migrar al radio; la fosa semilunar y su hueso intercalar central migró al radio?.

Existen patologías que evidencian estas alteraciones en la expresión de los genes Hox en el antebrazo y la muñeca (mano bot-zamba, enfermedad de Madelung)..

\section{ANATOMÍA}

\section{Estabilizadores de la región de la muñeca:}

Existen en el borde cubital de la muñeca, alrededor del pisiforme, varios elementos anatómicos que interactúan entre ellos para estabilizar el borde cubital de la muñeca ${ }^{10}$. En la porción cubital de la muñeca se pueden describir estabilizadores pasivos (ligamentos y fascias) y activos. Estos elementos anatómicos tienen mucha importancia en la estabilización de la porción cubital de la muñeca".

Los estabilizadores pasivos son el retináculo extensor, el suelo del quinto y sexto compartimento extensor, la cápsula dorsal, el ligamento radiocubital dorsal, el ligamento radiopiramidal dorsal, el ligamento colateral cubital y el fibrocartílago triangular. 


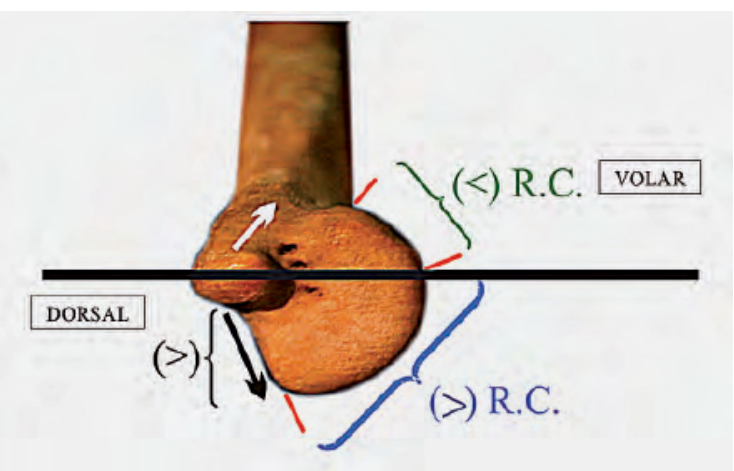

Figura 6. El radio de curvatura de la porción dorsal del cúbito es mayor. La existencia de diferentes radios de curvatura de las superficies articulares induce el movimiento del radio sobre el cúbito y lo hará siempre hacia el radio de curvatura menor y por tanto hacia la pronación.

Los estabilizadores activos son los tendones del Extensor cubital del carpo y Flexor cubital del carpo.

Todos los estabilizadores pasivos se insertan en la porción dorsal del cúbito distal, es decir, la porción cubital del carpo está sostenida desde el dorso del cúbito. Por eso cuando se lesionan estos ligamentos, la porción cubital del carpo cae hacia volar y este giro del carpo, altera la relación de la primera hilera del carpo con el radio.

\section{Sector interno de la muñeca}

El complejo ligamentario del sector interno de la muñeca, es muy importante en la biomecánica de la muñeca. El carpo está "suspendido" desde el cúbito distal, lo que le permite a esta zona tener múltiples movimientos de flexo-extensión y rotación, teniendo como eje al cúbito.

En la articulación radiocubital distal, la distancia de la estiloides cubital a las superficies articulares de la epífisis no son equidistantes. Es mayor la distancia volar, por eso los ligamentos volares son más largos y los ligamentos dorsales son más cortos.

La existencia de diferentes radios de curvatura de las superficies articulares induce el movimiento del radio sobre el cúbito y lo hará siempre hacia el radio de curvatura menor.

Cuando analizamos específicamente la morfología de las superficies articulares de la epífisis distal del cúbito, se evidencia los diferentes "radios de curvatura", lo que induce al deslizamiento articular y favorece los "movimientos diadocales" y la "rotación conjunta".
Estos producen un "giro automático" involuntario, inherente a la morfología de la superficie articular (c) Figura 6.

La actitud de reposo del antebrazo y la muñeca es la pronación. En esta posición no hay gasto energético; cuando realizamos la supinación, hay una acción muscular, por lo tanto, se produce un gasto energético. Cuando uno deja de supinar, automáticamente la muñeca cae en pronación de reposo.

Uno de los mecanismos por lo que la naturaleza se vale para lograr estos fines, es cambiando los radios de curvatura de las superficies articulares. Si quiere que una superficie se deslice sobre otra, en un sentido, disminuye el radio de curvatura en ese sentido y, lógicamente, induce el movimiento hacia el radio de curvatura menor.

El radio de curvatura de la cara volar de la epífisis distal del cúbito, es menor que el dorsal, por eso induce el movimiento de pronación y por eso la muñeca tiende a la pronación en una actitud de reposo

Los ligamentos de las articulaciones están diseñados y colocados estratégicamente para estabilizar los movimientos que inducen la disminución de esos radios de curvatura. En la articulación radiocubital distal el movimiento favorecido es el de pronación y por eso es estabilizado por fuertes ligamentos en el dorso de la articulación.

\section{Prono-supinación}

El segmento intercalar del miembro superior es el antebrazo y presenta dos articulaciones, una en cada extremo, para poder realizar la pronosupinación. Son dos articulaciones ligadas puesto que una no puede moverse si no lo hace la otra. Las diferencias morfológicas entre ellas se deben a que la naturaleza necesita una solución diferente para el desplazamiento y movimiento proximal y distal. (2) Figura 7 y (2) Figura 8.

\section{Cavidad Sigmoidea menor del Radio}

Cuando se analiza la morfología de la superficie articular de la cavidad sigmoidea (visto desde anterior a posterior) se evidencia que es oblicua (como un espiral) desde interno a externo. Por eso, cada vez que el radio prona sobre el cúbito, este tiende a ascender y cada vez que supina tiende a descender. Esta morfología ovoide favorece los movimientos diadocales y la rotación conjunta. (a) Figura 9. 

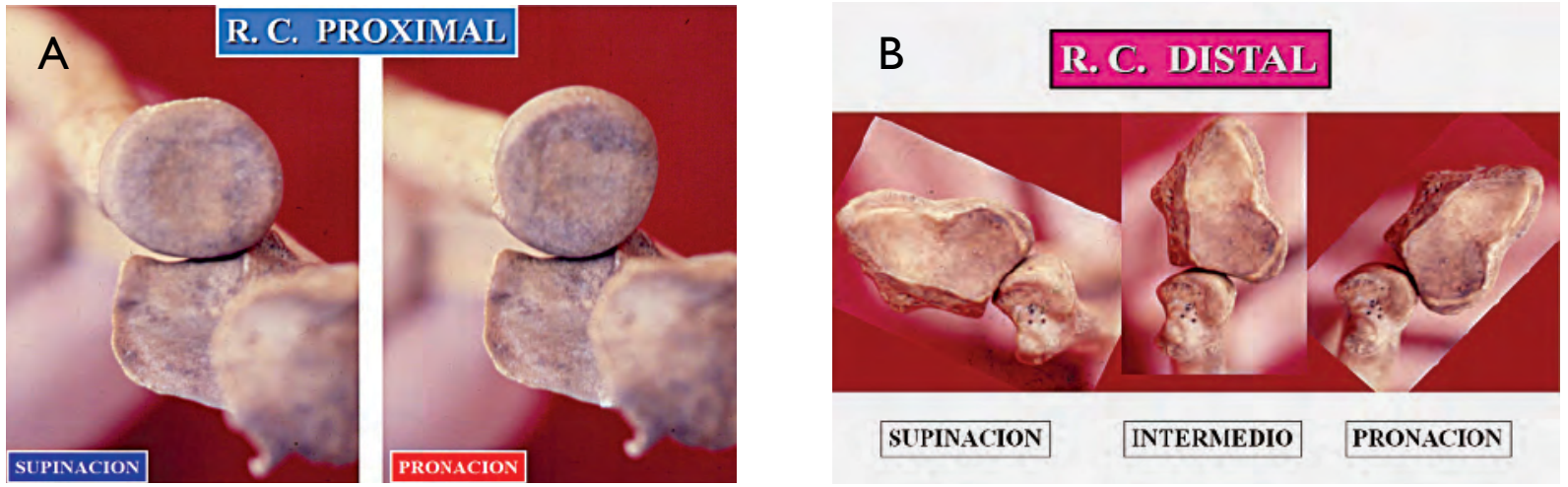

Figura 7.A. La articulación radiocubital proximal, tiene menos desplazamiento, por lo que es un "macho sobre una hembra". B. La articulación radiocubital distal, necesita más desplazamiento, por lo que es una "hembra sobre un macho".

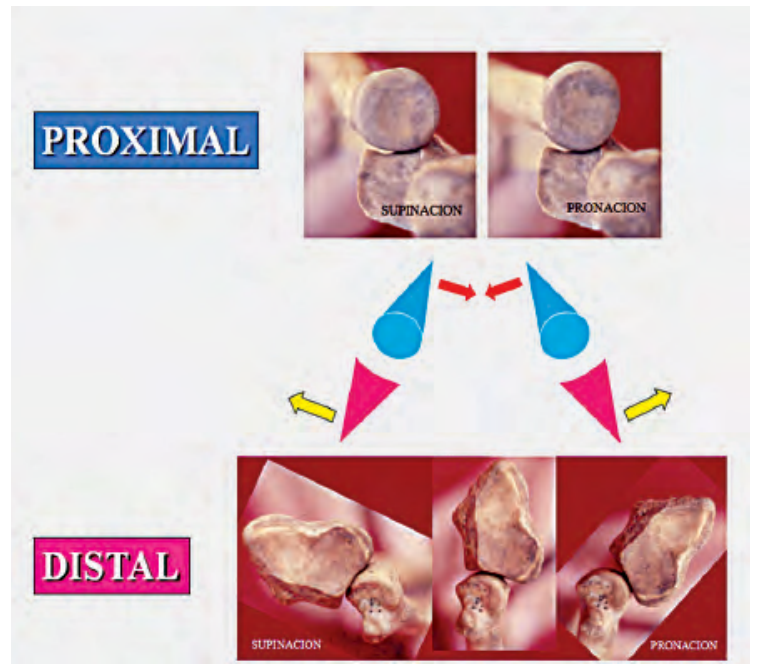

Figura 8. A pesar de ser "articulaciones ligadas" que trabajan al unísono, tienen una morfología diferente. La radiocubital proximal necesita más rotación que desplazamiento. La radiocubital distal necesita más desplazamiento que rotación.

La variación de la longitud del cúbito respecto al radio según exista una posición de pronación o supinación es importante en el momento del impacto, ya que la distribución de las fuerzas variará. También, es importante la desviación radial del antebrazo, que favorece las fuerzas de compresión en el sector externo y de distracción en el sector interno.

\section{PATRONES LESIONALES DE LAS FRACTURAS DE RADIO}

En la literatura se describe que las líneas de fuerzas en la muñeca normal, pasa el $80 \%$ por el radio y en un $20 \%$ por el borde cubital. Se sabe que esta distribu-
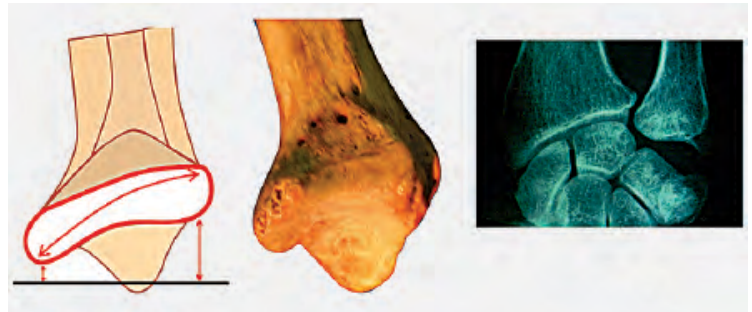

Figura 9. La superficie articular de la cavidad sigmoidea es oblicua (como un espiral). Por eso, cada vez que el radio prona sobre el cúbito, este tiende a ascender y cada vez que supina tiende a descender.

ción varía en función de la longitud del cúbito (minus o plus), pero no se tiene en cuenta las fuerzas de distracción, que son mayores en la región cubital (sector interno) de la articulación de la muñeca.

La arquitectura ósea del sector radial de la muñeca permite absorber mayor cantidad de fuerzas de compresión. Mientras que el sector cubital, está adaptado para fuerzas de distracción, (mediante estabilizadores pasivos y activos como se ha mencionado).

En el momento del traumatismo es importante la posición de la muñeca y si el impacto fue en la región tenar o hipotenar. Esto determina el punto del carpo que transmite las fuerzas por compresión y qué sector se colapsa en el primer momento (sector externo o sector central). Si la energía traumática continúa y la muñeca se inclina en pronación y desviación radial, se desencadena la segunda lesión, que es por distracción sobre el sector interno@ Figura 10.

La magnitud de esta segunda lesión va a estar en relación con el tipo de lesión en los otros dos sectores y 

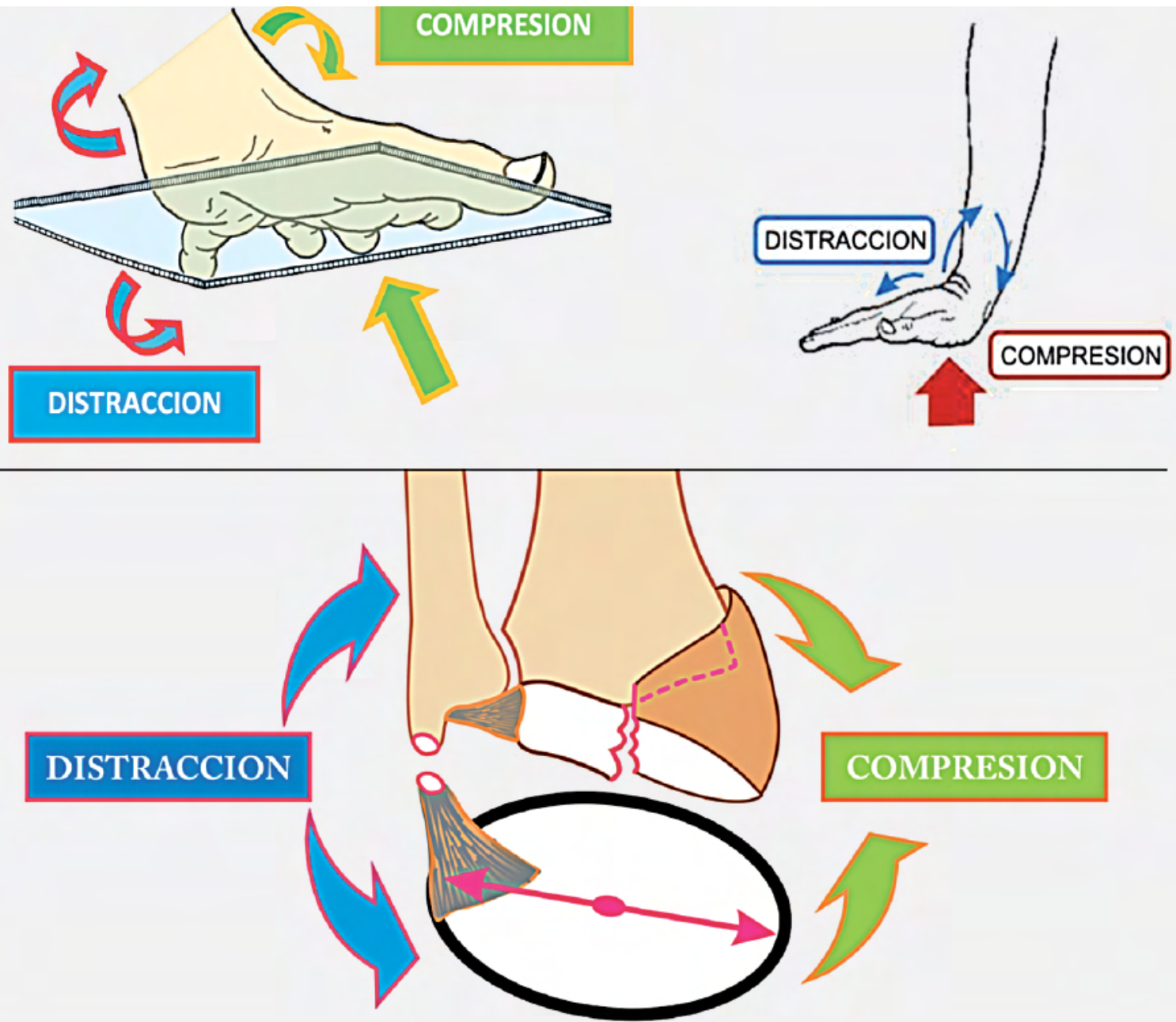

Figura \| 0. Posición habitual de la muñeca en el momento de la caída. Esta posición es debida a que al único reflejo primitivo que continúa siempre presente es el "reflejo de paracaidista". Cuando se va a impactar contra el suelo, se colocan las manos en defensa (esto es ancestral, primitivo y es involuntario). El centro de rotación está próximo a la cabeza del hueso grande. Se produce compresión en el segmento radial y distracción en el cubital.

se relaciona especialmente con que exista o no una lesión del sector central. Si se valoran radiografías de muñeca en pacientes que simulan una caída, se puede observar cómo el sector radial actúa como sector que soporta compresión, mientras que el cubital soporta distracción. (8) Figura II.

Las lesiones de la estiloides del cúbito están asociadas a las fracturas del radio en 2/3 de los casos y se produce esta avulsión, puesto que el cúbito continúa el movimiento de inclinación y la tracción se produce generalmente a nivel de la estiloides cubital.

Por todo lo mencionado es frecuente en los traumatismos que en el borde radial del carpo y la muñeca sucedan fracturas, mientras que en borde cubital se produzcan lesiones ligamentosas (a) Figura 12.
Los distintos tipos de patrones lesionales y su diagnóstico se tratará de forma más extensa en la parte Il del presente trabajo.

\section{NUEVA CLASIFICACIÓN DE LOS SECTORES DE LA MUÑNCA:}

La nueva clasificación propuesta surge de la interpretación de los cambios que sucedieron en la muñeca basados en el estudio de la evolución filogenética y embriológica.

Se describen tres sectores en la muñeca: cubital, central y radial. Cada uno de ellos presentan diferentes orígenes filogenéticos, anatómicos, biomecánicos y funcionales (d) Figura 13. 


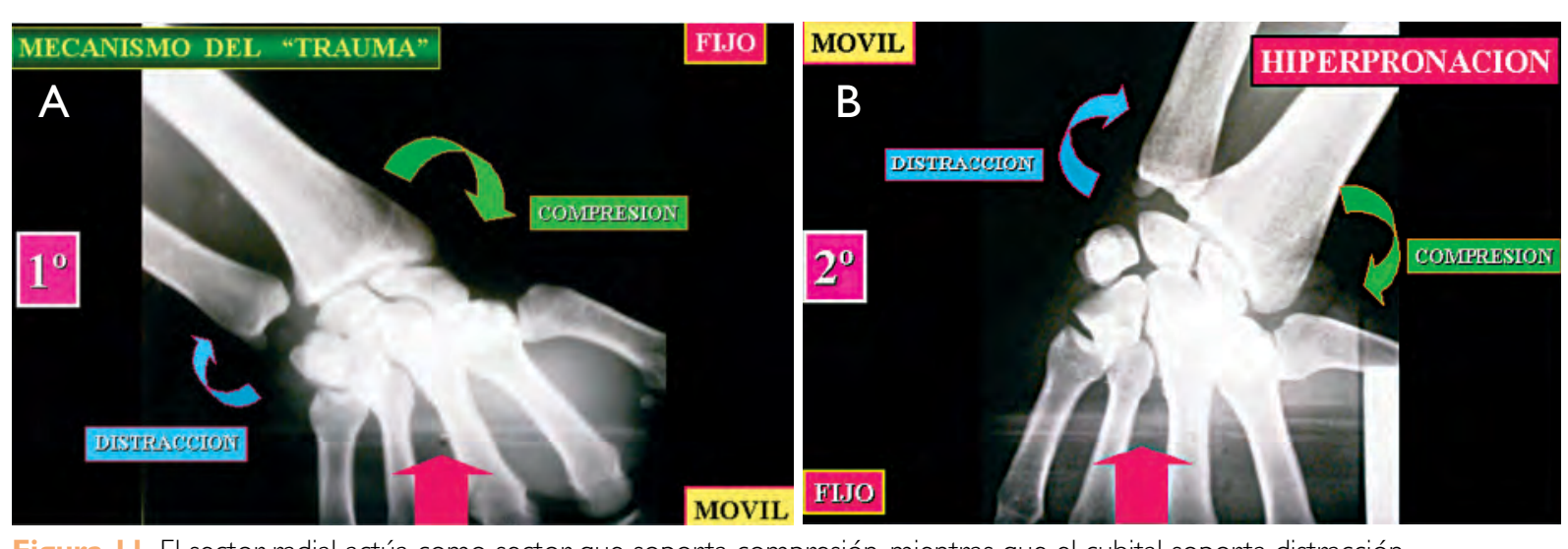

Figura. || || El sector radial actúa como sector que soporta compresión, mientras que el cubital soporta distracción.

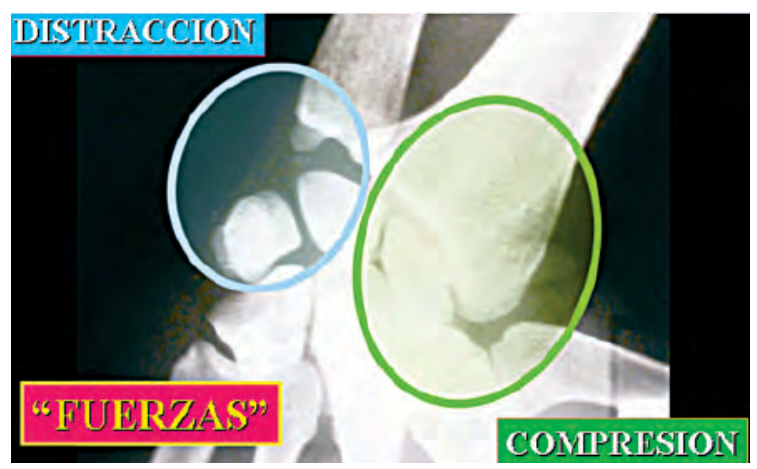

Figura I 2. Las lesiones y los desplazamientos dependen del "punto de aplicación de las fuerzas". Por eso en el borde radial del carpo y la muñeca suelen suceder fracturas, mientras que en borde cubital ocurren lesiones ligamentosas.

\section{CONFLICTOS DE INTERESES}

Los autores declaran no tener conflictos de intereses.

\section{BIBLIOGRAFÍA}

I. Hildebrand, M. Anatomía y embriología de los vertebrados. Mexico. Editorial Limusa; 1991.

2. Kardong K, Benito S. Vertebrados: anatomía comparada, función, evolución. $2^{\circ}$ edición. Madrid: Mc Graw-Hill; 1999.

3. Pierre PG. L'Evolution du vivant, matériaux pour une nouvelle théorie transformiste. Paris: Albin Michel; 1973

4. Youmg IZ. La vida de los vertebrados". Barcelona: Ediciones Omega; 1980.

5. Carlson BM. Embriología humana y biología del desarrollo. $2^{\text {a }}$ Ed. Madrid: Ediciones Harcourt-Mosey; 2000.

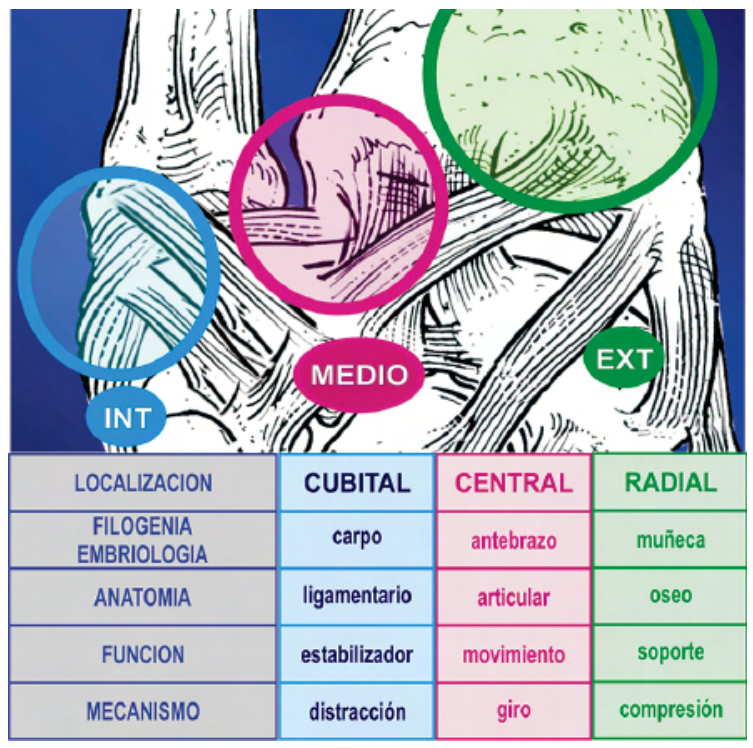

Figura 13. El sector cubital es ligamentario, y en el actúan fuerzas de "distracción". El sector central, es articular y en él se producen "giros". El sector radial, es óseo y en él actúan fuerzas de "compresión".

6. Gilbert, Scott. Biología del desarrollo. $7^{\circ}$ edición. Buenos Aires: Ediciones Panamericana; 2005.

7. Moore K, Persaud,TV, Shiota K. Atlas de embriología clínica. Madrid: Ediciones Panamericana; 1994.

8. Greulicht WW, Pyle Sl., Radiographic atlas of skeletal development of the hand and wrist. California: Stanford University Press; 1959.

9. Rotella. "Evolución y Fisiopatología Fractura de Muñeca" Congreso Argentino de Ortopedia y Traumatología. 2006.

10. Williams P, Gray H, Bannister, LH.Anatomía de Gray: bases anatómicas de la medicina y la cirugía. $38^{\circ}$ edición. Madrid: Churchill Livingstone: Harcourt Brace; 1998.

I I. Zancolli EA., Cozzi E. Atlas de Anatomía Quirúrgica de la Mano. Editorial Panamericana SA. 1993. 